\title{
INSÔNIA OU A POBREZA NÃO DESCANSA*
}

NEITHER INSOMNIA NOR POVERTY RESTS

Roberto Vecchi ${ }^{1}$

ORCID 0000-0001-5982-0810

\author{
Éderson de Oliveira Cabral² \\ ORCID 0000-0002-3393-8340 \\ ${ }^{1}$ Universidade de Bolonha, \\ Bolonha, Itália \\ ${ }^{2}$ Universidade Feevale, \\ Novo Hamburgo, RS, Brasil
}

\section{Resumo}

Este trabalho visa analisar a relação entre literatura e pobreza, por meio de sua forma simbólica, no conto de Roniwalter Jatobá intitulado Insônia, presente em Contos Antológicos de Roniwalter Jatobá, organizado por Luis Ruffato. Para isso, trabalha-se com diversos conceitos que servem como aporte teórico e, posteriormente, como categorias críticas de análise. Neste estudo, etimologias, metáforas e conceitos de Giorgio Agamben, de Hans Blumenberg e de outros teóricos, que servem como figuras de pensamento, são implicados para refletir sobre a representação da pobreza, da miséria e do trabalho dentro da literatura e cultura brasileira.

Palavras-chave: Pobreza, Miséria, Trabalho, Roniwalter Jatobá.

\section{Abstract}

This study aims to analyze the relationship between literature and poverty, through its symbolic form, in Roniwalter Jatobás short story Insônia, part of the anthology Contos Antológicos de Roniwalter Jatobá, organized by Luis Ruffato. For this purpose, we work with several concepts that serve as theoretical input and, subsequently, as critical categories of analysis. In this study, etymologies, metaphors and concepts by Giorgio Agamben, Hans Blumenberg and other theorists thatserve as figures

\section{Riassunto}

Questo lavoro si propone di analizzare il rapporto tra letteratura e povertà, attraverso la sua forma simbolica, nel racconto di Roniwalter Jatobá, dal titolo Insônia, presente in Contos Antológicos de Roniwalter Jatobá, editato da Luis Ruffato. Per fare questo, ci si appella a diversi concetti che servono come input teorici e, successivamente, come categorie critiche di analisi. Etimologie, metafore e concetti di Giorgio Agamben, Hans Blumenberg, insieme ad altri teorici e figure di pensiero, vengono chiamati

\footnotetext{
* O presente trabalho foi realizado com apoio da Coordenaçấo de Aperfeiçoamento de Pessoal de Nível Superior - Brasil (CAPES) e no âmbito do projeto "MEMOIRS - Children of Empires and European Postmemories".
} 
of thought, are implicated to reflect on the representation of poverty, misery and work in Brazilian literature and culture.

Keywords: Poverty, Misery, Work, Roniwalter Jatobá. in causa allo scopo di riflettere sulla rappresentazione della povertà, della miseria e del lavoro all'interno della letteratura e della cultura brasiliana.

Parole chiave: Povertà, Miseria, Lavoro, Roniwalter Jatobá.

[...] o azar, que é ter nascido pobre em um país como o Brasil, onde poucos desfrutam (por quanto tempo ainda?) de um bem-estar que não é bem nem estar (SANTOS, 2012).

\section{Pobreza e trabalho}

Surpreende que a pobreza ou a miséria sejam palavras com um forte impacto moral. $\mathrm{Na}$ verdade, um impacto que provoca constrangimento ou horror. Desde o nome, portanto, surge um limite - ou um impasse de representação. Um primeiro elemento que contribui para entender a fenomenologia de uma reação, a qual surge perante a extrema mendicidade, decorre da matriz etimológica do próprio nome. Mais uma vez, as etimologias surgem como uma figura do pensamento que alimenta a reflexão crítica. Antes de tudo, é importante uma distinção: em termos de semântica histórica pobreza e miséria não são palavras coincidentes. Pobre (de pauper) no latim representa, diferentemente de inops e miser, alguém que, mesmo em um quadro de exiguidade, possuía alguns meios, os quais lhe conferiam reconhecimento social. Pelo contrário, miser era quem vivia em condiçóes de carências absolutas (CORTELAZZO; ZOLLI, 1999, p.987). É significativa, na perspetiva da apreensão da sua carga simbólica, a etimologia de miser, pois possui uma raiz sânscrita $m i$ - que indica diminuir, destruir (a mesma que possui o termo menos). Nessa raiz, após a passagem do grego misos ( $\mu$ ĩoo $)$ que significa ódio, aversão, nota-se a projeção desse sentimento negativo - de repulsão do que se descreve - que em latim se expressa como miséria, no sentido próprio não somente de pobreza absoluta, mas também no sentido figural de desgraça, aflição. Ou seja, poderíamos interpretar, graças a essa reconstrução, como na própria origem linguística e histórica da palavra, que miséria incorpora também uma conotação moral e negativa. $\mathrm{O}$ misero é obsceno, linguística, cultural e historicamente. Náo surpreende o seu apagamento no plano da representação, sobretudo porque a representação se estrutura a partir de um código de poder. 
O distanciamento na observação da miséria possui também um outro elemento caraterizador, o qual explica ainda mais a procura de distanciamento presente na ordem das representaçóes culturais. Advém da metaforologia de Hans Blumenberg (1985, p. 39-40) e pode ser descrita como uma das metáforas mais contundentes sobre a modernidade; a pobreza evoca, de fato, a metáfora do naufrágio que Blumenberg recupera do De rerum natura, de Lucrécio (Proemio do Livro II, 1-4), que descreve as transformaçóes no moderno. Mas é a sua configuração clássica que aqui interessa; o sábio epicureu, o espectador do naufrágio, sente um gozo ao assisti-lo de longe, porque percebe, pela distância, que ele não está envolvido, contudo pode afastado contemplá-lo, na sua patente alteridade.

\section{Suave, mari magno turbantibus aequora ventis, e terra magnum alterius spectare laborem; non quia vexari quemquamst iocunda voluptas, sed quibus ipse malis careas quia cernere suave est ${ }^{1}$.}

A pobreza produz o efeito do naufrágio em relação ao espectador do mundo clássico: proporciona um prazer inefável a não identificação vistosa com a população carente e tem acesso às fontes narcisísticas do prazer individual, que produz o outro, no sentido da impossibilidade de identificação, sem margens de ambiguidade.

Dentro de um contexto mais específico como o Brasil, situando o problema geral, a literatura brasileira atesta, com uma extraordinária força crítica, multíplices casos do recalcamento da pobreza da cena principal, em que se espelha o idealismo vazio de pertença a uma pressuposta nação. Um dos exemplos canônicos mais evidentes - mas o repertório poderia estender-se quase ad infinitum - é um breve conto de Rubem Fonseca, no conhecidíssimo Feliz ano novo ${ }^{2}$. Trata-se de $O$ outro, um conto no qual se percebe que o poder se funda na vida nua ${ }^{3}$ do excluído, como atesta de maneira incisiva o seu assassinato sem culpa: "que culpa eu tinha de ele ser pobre?" (FONSECA, 1989, p. 90). O pobre, nesse conto, é incluído de novo na condição de corpo massacrado, de carne, a qual revela os perturbadores traços da sua invisível identidade de menino, que emerge no desfecho, saindo da sua perturbante

1 Quando no mar grande os ventos perturbam águas tranquilas, / olhar da terra o grande sofrimento de um outro: lá há prazer;/ não que é um prazer agradável o fato de um outro sofrer,/ mas é prazer olhar aqueles males de que estás livre (tradução nossa).

2 É possível, também, destacar o número de ocorrências da palavra "pobre", no conjunto de Feliz ano novo, as quais são empregadas como algo a ser desaprovado, desviado, rejeitado, repudiada e condenado (forclusão).

3 Conforme Giorgio Agamben (2007), em Homo Sacer. 
obscenidade, do seu potencial de perigo, que existe somente na mente paranoica do narrador "doutor".

No quadro das representaçóes de classe na cultura brasileira, abrindo assim a uma generalização muito ampla, destaca-se outro elemento que remete para condiçóes referenciais específicas. A mesma censura moral que se encontra na pobreza se estende também na relação com o mundo do trabalho. Encenando uma espécie de paradoxo que apenas se explica por fraturas presentes na formação do país, o trabalho assalariado deveria ser o que emancipa da pobreza e confere uma dignidade social. Sempre em termos etimológicos, pode-se notar que entre a raiz que forma a palavra inops, ops, ou seja, meio, recurso (o pobre é sem meios) há um elo semântico com opus, obra, já atestado por Cicero "omni ope atque opera eniti" trabalho ou a obra, em particular, manual, salvo as inúmeras exceçóes que no plano das artes e da cultura se manifestaram do ponto de vista social, tem provocado uma rejeição moral próxima daquela da pobreza.

Não cabe, no perímetro deste artigo, enumerar as razóes do que, no sentido comum, seria uma alteridade assimilativa. No entanto, é oportuno notar como funciona produzindo uma invisibilização do mundo do trabalho aproximado daquele da miséria e submetido à mesma ordem de censura moral, fora daquele imenso e, às vezes, ousado pantheon das vítimas que é a literatura brasileira e, de modo geral, as artes do Brasil. Essa observação permite pensar em conjunto, no plano das representaçóes problemáticas, o eixo miséria e trabalho. A moldura é representada pelo que poderíamos chamar, referido à constelação Lacan-Spivak", de "forclusão social" a que parecem subordinadas as representaçóes da condiçáo da pobreza e do trabalho e que se resume na metáfora do espectador distante do naufrágio. Seu funcionamento se perceberia pelos rastros residuários do sujeito que a expulsão - nesse caso uma expulsão historicamente constituída - deixa no real e que ocorre por meio de umoco, de um buraco, de uma invisibilidade, de uma preclusão, justamente (SPIVAK, 2004).

Nesse sentido, a literatura funciona como um arquivo que oferece uma inesperada chance de emersão do que de outro modo se perderia definitivamente ou se dissolveria no pó indistinto da história - essa linha traça não somente um outro compromisso das ciências humanas com o contexto factual, mas também incide em profundidade na noção de canône. Em variados momentos, a literatura brasileira se interrogou sobre o papel político da sua ação na construção de arquivos alternativos dos seus imaginários.

4 "Agir com todo meio e todo esforço" (CASTIGLIONI; MARIOTTI, 1990, p. 778).

5 Conforme Gayatri C. Spivak em Critica della ragione postcoloniale e Jacques Lacan, em As formaçôes do inconsciente. 
No caso do Brasil, há algumas referências imprescindíveis. Antes de tudo, em uma época ainda conturbada pelo fim da ditadura, cabe destacar o volume coletivo organizado por Roberto Schwarz, Os pobres na literatura brasileira, de 1983, obra que, por meio de um repertório diacrônico de ensaios de diversos autores, articula uma visão alternativa da literatura brasileira, a qual centraliza a radicalidade da questão estética. Depois, no volume de Alfredo Bosi, Cultura brasileira, de 1987, o capítulo escrito por Zenir Campos Reis, O mundo do trabalho e seus avessos, no qual emerge, além da distorsão aparente ou até de ocultamento da pobreza no plano monumental do cânone de uma literatura que, como regra geral, tem a elite como principal público-leitor, um outro olhar sobre as formas literárias, como por exemplo a da malandragem, que operaria como uma forma indireta, mas abertamente crítica, contra a inivisibilidade dos mundos dos pobres e dos trabalhadores, em um contexto no qual não são separáveis as dimensóes da norma e da exceção. Assim, nesses textos emerge a procura de indenização sobre o passado, comprometida para repensar o cânone por meio de uma outra perspectiva, a da subalternidade e da exclusão, valorizando o seu potencial discreto de resiliência perante as restriçôes macroscópicas da dominação (VECCHI, 2014).

Essa superação da forclusão estrutural dos mundos que ficaram fora da cena das representaçóes proporciona as condiçóes para elaborar uma outra história literária. Assumindo como ponto de diálogo a literatura italiana, que apresenta também uma complexa história da industrialização e das relaçóes de classe, a subversão do cânone pelo contexto social discriminado cria o espaço para uma tradição significativa de literatura operária e também operaista ${ }^{6}$ : o exemplo mais conhecido é Metello, de Vasco Pratolini (1955), na linha de uma tradição contínua chegando até à contemporaneidade, como atesta o belíssimo romance La dismissione, de Ermanno Rea (2002), sobre a desmontagem do polo siderúrgico de Bagnoli, na região de Nápoles, onde, na desmontagem da máquina que é vendida para a China, o operário encontra, nas partes da fábrica desmanchada, os cacos perdidos da uma história pessoal e comunitária.

Nesse contexto, o papel da literatura vai além da sua primeira preocupação estética. Desmonta e relativiza a rejeição moral que existe perante a pobreza e o trabalho, e constrói um outro universo de valores no qual o tema político do resgate, inclusive também da revolta - como suspensão do tempo histórico, mesmo sem chegar à fratura da revolução -, insinua-se nas entrelinhas de uma representação por sua vez emancipada dos interditos e costruçōes de um cânone classista.

6Termo vinculado ao operaísmo, corrente política e teórica do pensamento marxista que surgiu na Itália no começo dos anos 1960 . 
A literatura brasileira tem uma característica: caso se compare a história da literatura brasileira com a história do Brasil, percebe-se que a história da literatura faz um percurso que não coincide com a sua própria história; pelo contrário, faz, em muitos casos, um percurso pelo avesso. Por exemplo, se se destaca a pobreza, o pobre ou a vítima, quais são os casos em que se percebe que há uma dificuldade de reconhecê-lo?? . Essa questáo retórica mostra a opacidade, ou melhor, a impossibilidade de ver e reconhecer a vítima presente na sociedade, as vítimas que a sociedade tem, sobretudo nos momentos mais críticos da história ${ }^{8}$. O pobre e o trabalhador podem ser relacionados ao homo sacer, figura central do pensamento do filósofo italiano Giorgio Agamben. O homo sacer representa uma vida totalmente apta de ser executada (AGAMBEN, 2007) e pode ser não só "os judeus nos campos de concentração, os prisioneiros de Guantánamo, os que não têm documentos, os que pedem asilo, que aguardam em um local neutro para sua deportação ou também os doentes em estágio terminal nas UTIs, que apenas ainda vegetam presos aos seus tubos", mas também "os que estáo às margens da sociedade" (HAN, 2018, p. 45-46), os que são excluídos, e inclui-se os que se movimentam na condição de trabalhadores na sociedade de trabalho?.

É por isso que entra em cena a literatura. A literatura como consciência crítica, nas suas vozes mais dissidentes. A literatura, nesse caso, funciona como uma consciência crítica de uma sociedade que parece ter construído uma resistência, uma resiliência, ou melhor, a potencialidade de ser incapaz para reconhecer os próprios padecedores das misérias e pobrezas alastradas, ampliadas e conservadas. Caso se contextualizem essas questóes no quadro da atualidade, o pobre ou o trabalhador (figuras híbridas, coincidentes) são as vítimas de uma modernização estridente e estritamente excludente. Caso a sociedade reconheça o pobre ou o trabalhador como vítimas, ficaria evidente a impossibilidade de se manter os privilégios e os privilegiados. Há, assim,

7 A ditadura militar brasileira é um caso, pois parte da sociedade não reconhece a vítima como o torturado pelo regime. O que está atrás da situação de exceção atual é (tam)bem isso, a não aceitação dessa ideia de que houve golpes, de que houve torturas, de que os torturados são vítimas. Pode-se, além disso, levantar a questão do comunista (entre uma série de outros personagens/figuras sociais) como bode expiatório (betê noir, whipping boy) que a ele é atribuída toda uma série de culpas que não tem.

8 No contexto da sociedade brasileira, é necessário um bode expiatório (lembra-se, neste momento, de Os sertôes). Especula-se, em todos os sentidos do verbo especular, que isso é uma herança da condição colonial, pois é como se a sociedade brasileira precisasse sempre de bodes expiatórios pela incapacidade que tem de reconhecer as vítimas, isto é, a culpa deve ser jogada em algumas figuras sociais, que acabam sendo acumuladoras de energia negativa: o comunista, na ditadura militar, o petista, no contexto atual. Em suma, são os espectros, como ameaça, agitados para não se realizar o esforço de reconhecer a vítima.

9Na sociedade disciplinar que propôs Michel Foucault (2009), e que é retomada por Byung-Chul Han (2018) para desenvolver a proposta da sociedade do cansaço, ou do desempenho. 
uma explicação sociológica da interdição de acesso ao reconhecimento e à consciência de que o pobre e o trabalhador são as vítimas. Quais grupos sociais reconhecem essas figuras interditas como vítimas? ${ }^{10}$

Dentro do mundo do trabalho, transcorrendo os séculos XX e XXI, há discursos sobre os cortes dos direitos, da reforma trabalhista, da reforma previdenciária, entre outros. Por isso, aqui tem-se um campo, o da sociedade que tem uma dificuldade de reconhecer os pobres (como as vítimas), os interditos, os exauridos, os últimos (figuras sociais todas coincidentes), mas também poder-se-ia dizer os invisíveis. Por que se propóe neste momento a invisibilidade dessas pessoas? Pois os invisíveis não colocam em crise um sistema de privilégios. Se os invisíveis fossem reconhecidos como vítimas, a consciência de uma pessoa ${ }^{11}$ (em relação a uma náo pessoa ou a um invisível) poderia ficar perturbada. Uma pessoa poderia continuar a viver como antes, porém com mais perturbaçóes ou turvamentos. De fato, esse mecanismo é autodefensivo. Portanto, a literatura, nessa situação, assume a função de mostrar os invisíveis, os que são considerados não pessoas, as pessoas que têm a vida desqualificada (AGAMBEN, 2007), o homo sacer, as vítimas.

A literatura brasileira, muitas vezes, é um lugar de reconhecimento e de emersão da vítima, a qual pode ser vista como o homo sacer. Roberto Vecchi (2017), em Memorials of Words, aponta que o fantasma na literatura brasileira é a própria vítima, tanto na sua esfera de derrota, quanto no âmbito da oferenda sacrificial ou do aprisionado, encarcerado (em estado de prisão). A vítima pode ser o subalterno, o subordinado, pois, segundo Vecchi (2017), nos grandes textos literários brasileiros emerge a vítima, ou da vítima (por exemplo, Os sertóes, de Euclides da Cunha ou Vidas secas, de Graciliano Ramos).

Mas, tendo a vítima, o homo sacer, ainda assim há algo de peculiar, muitas vezes é o autor que faz falar o subalterno, plasmando no texto uma espécie de vocalização da vítima ${ }^{12}$. Não obstante, reconhecê-las é algo que a sociedade brasileira não fez e não faz. No país, não há uma política de restituição. É como se a literatura desempenhasse não apenas a função de ser um grande arquivo de mundos, ou melhor, um arquivo estético, cultural, memorial (como em todas as literaturas), mas também como se tivesse uma espécie de função suplementar, que é de fixar uma consciência crítica, a qual a sociedade brasileira (ainda) náo tem (de modo impactante e transformador).

10 Um deles é o grupo comunista. Outros grupos seriam aqueles de concepçáo religiosa e filosófica, que têm consciência da vítima, pela história das perseguiçóes, ou que têm a vítima como centro da história, uma visão cristológica, por um lado, ou a redenção dos oprimidos, por outro.

11 Ver o conceito de pessoa, como propôe Alexis de Tocqueville em Democracia na América.

12 Pode-se trazer aqui Gayatri C. Spivak que, em Pode o subalterno falar?, primeiramente, aponta que o subalterno não pode falar, que é uma conclusăo trágica, pois quem fala é o autor, que lhe dá voz, trazendo a questão da escrita literária. Após, no Crítica da razão pós-colonial, Spivak dirá que o subalterno (pode) fala(r) pelo corpo, náo pela voz. 
É, talvez, por essa razão que se encontra o subalterno (sub-outro, sub-alter, "sub-homem" * "super-homem"13) de maneira macroscópica, numa sociedade que não tem cidadania garantida a todos, não tem voz (ou não tinha voz), oscilando nos planos do real, da falsificação e da testemunha, pois a vítima gera uma história, ou, pelo menos, uma narração de identidade (VECCHI, 2017), tantos dos sujeitos subalternos, quanto dos soberanos.

Tem-se, ainda, no percurso da literatura brasileira, toda uma literatura como "o sorriso da sociedade" ${ }^{14}$, pois há toda uma produção literária que exalta a(s) elite(s). A literatura, no Brasil, é/era produzida para uma elite consumadora e para um poder consumidor. Mas aí há, também, a força crítica da literatura, e sobretudo a "grande" literatura brasileira é um produto que surge à margem do mercado, a qual consegue conjugar a estética com a ética. Tem-se isso, no Brasil, na sua história literária, não obstante, também se tem o contrário, o outro lado, uma espécie de avesso - "o avesso do mesmo lugar"15.

Contudo, a literatura brasileira é um espaço de contrapoder, que escreve, em alguns casos, uma espécie de mundo alternativo, quiçá mais real que o real, que será enunciado por meio dos textos. Portanto, a literatura tem a capacidade de captar tais situaçóes de crise e es/inscrevê-la ${ }^{16}$, como o Vecchi (2017) exemplifica em Memorials of Words.

\section{Insônia, um conto de Roniwalter Jatobá}

A pobreza, como visto anteriormente, não é a menina dos olhos da literatura brasileira e, embora faça apariçóes nos textos de tantos autores ${ }^{17}$, não é o tema mais recorrente. Quando é representada nas obras, provoca

13 Como diz Agamben (2007, p.31), no capítulo A testemunha.

14 No começo do século XX, a literatura seria "o sorriso da sociedade", expressão do escritor Afrânio Peixoto, pois naquela época a literatura pairava nos salóes da elite, sempre intocada e pura, travestida de luxo, literalmente sem ceder lugar para o povo e suas dores.

15 Verso do samba-enredo da Mangueira, campeá do Carnaval do Rio de Janeiro 2019, intitulado História pra ninar gente grande.

16 Machado de Assis, no conto Pai contra mäe, Lima Barreto em diversos contos, e Euclides da Cunha nos seus textos são exemplos dessa captura do contrapoder; ii) no modernismo, tem uma (re)aproximaçáo da elite, porém Mario de Andrade, em uma série de textos de 1942, quando crítica o modernismo diz:" [...] mas isso ficará para outro futuro movimento modernista, amigo José de Alencar, meu irmão. Nós fracassamos", pois se percebe que não se entendeu onde estava o povo; iii) Guimarães Rosa, em $O$ recado do morro, mostra que são os marginais que salvam uma vida, porque as comunicaçôes formais não funcionam. Esse contrapoder também está no grupo do Romance de 30, porque nele há a questão do subalterno, que chega à contemporaneidade. O Recado do moro é emblemático, pois quem decodifica as comunicaçôes é quem está na margem da sociedade. Há, nesse texto, uma espécie de mundo alternativo, no qual a comunicação funciona dentro de uma outra lógica exótica (pois fora da ótica) e excêntrica (fora do centro).

17 Pode-se trazer à lembrança a retomada atual da obra Quarto de despejo, de Carolina Maria de Jesus, ou do célebre conto Uma vela para Dário, de Dalton Trevisan. Também, dentro da literatura brasileira contemporânea, podem-se listar aqui não somente Hora da estrela, de Clarice Lispector, Memórias, de 
impacto, capaz de chamar a atenção dos interessados por esse argumento ${ }^{18}$; aos demais, passa despercebida. Apesar de ser um tema que se repete ao longo da história da literatura brasileira, todavia em termos de números de recorrências não é impactante ${ }^{19}$, mas ela está aí.

Dessa forma, nesta sessão, mostra-se como a pobreza não é apenas excluída, rejeitada e criminalizada na sociedade, mas também como ela está impressa nas páginas de Insônia, conto de Roniwalter Jatobá, em Contos Antológicos de Roniwalter Jatobá, com organizaçáo de Luiz Ruffato e publicado em 2009.

O conto, o qual em sua cenografia consegue fazer coincidir a pobreza, o pobre, o trabalho, o trabalhador e a violência em suas diversas formas, inicia com o narrador-protagonista, indagando à mãe sobre o seu nome, Otto. Ambos vivem juntos em uma casa que tem seus ambientes separados por cortinas, com frestas no telhado, com um banheiro externo, compartilhado com outras famílias, e possuem uma televisão que fica encostada na cabeceira da cama e um cachorro que nem para no pátio. Em uma noite, Otto remói pensamentos e tem uma inquietação em relação ao seu próprio nome, logo não consegue dormir: "Espantado de vez, nada de vontade de dormir. Não queria mudar de nome, nada, pensei” (JATOBÁ, 2009, p. 33). Otto não consegue dormir, faz diversas lucubrações e vê sua mãe já frágil, em um repouso daquele que foi exaurido pelo desgaste do tempo e do trabalho: "[...] fui na cama dela, botei uma calça velha em cima dos seus pés frios parecendo gelo, e fiquei olhando ela, o corpinho cansado de muita labuta" (JATOBÁ, 2009, p.34). Otto trabalha em uma fábrica, e a sua insônia o preocupa, porque teme o seu estado sonolento no seu próximo dia laboral. Dessa forma, toma coragem, veste-se e sai à rua tomar um ar, pois pensa que uma volta faria o seu sono retornar. Nessa caminhada noturna, Otto é tomado pelas lembranças do pai, pobre e trabalhador, que morreu em uma construção em um acidente de trabalho, mas é surpreendido por um homem armado, que lhe pede os documentos. Primeiramente, Otto sente um alívio por reconhecer que o homem é um possível policial, que não está sozinho, seus colegas o acompanham dentro de um carro que ilumina a rua escura. Sem documentos, passa por uma abordagem, os prováveis policias o revistam, e o alívio se transforma em medo, pois na mente de Otto ecoam rememoraçóes

Gregório Bezerra, mas também as obras de José Lins do Rego, de Raquel de Queiroz, de Graciliano Ramos, de Jorge Amado, de Domingos Pellegrini, de Ruben Fonseca, de Luis Ruffato, entre outros.

18 Em relação à crítica literária, encontra-se Os pobres na literatura brasileira, conjunto de textos, organizado por Roberto Schwarz, e recentemente Literatura e exclusão, uma coletânea de artigos organizada por Laeticia Eble e Regina Dalcastagnè.

19 Regina Dalcastagnè, em um Mapa de ausências, capítulo da obra Literatura brasileira contemporânea, mostra, em números, a representação da pobreza ao longo do tempo dentro da literatura brasileira. 
dos casos que as pessoas contam desses encontros no meio da noite: “[...] o corpo esquentou no medo, ferveu nas lembranças casos contados do que essa gente apronta no meio da noite" (JATOBÁ, 2009, p. 36). Na interpelaçáo, Otto se justifica, mas suas palavras não são ouvidas; apenas o seu nome, que se torna motivo de deboche: "[...] o que a gente faz com o doutor Otto?" (JATOBÁ, 2009, p. 37). O insone é agredido, um homem dentro do carro comanda: "[...] dá um cascudo e manda o seu Otto dormir [...]" (JATOBÁ, 2009 , p. 37). Após a agressão, Otto espera mais violência, mas não acontece. Liberado pelos homens, sai correndo em direção à casa, chuta seu cachorro, estanca o choro, e o sangue que sai de seu nariz. A mãe, que estava dormindo, desperta e pergunta se está na hora de acordar e ir trabalhar; Otto responde que apenas tinha ido ao banheiro, deita-se preocupado com o relógio que logo anunciará a hora de despertar e ir ao trabalho e pensa no seu próprio nome que "[...] só era visto em padre. Ou era em lorde? Onde todo mundo tinha o nome conhecido, lá vinha o meu, Otto! Isso lá era nome?” (JATOBÁ, 2009, p. 38).

O narrador-personagem levanta reflexões sobre o seu nome, e não por acaso, pois era inusitado nos seus espaços de circulação. Não era por menos, pois o nome, no conto, exerce uma força de contradição com a pobreza que o cerca: Otto significa rico, próspero. Além disso, Otto serve como hipocorístico de nomes germânicos iniciados pelos elementos od ou ot, tais como Audo, Odo, Otton. Essas partículas od e $o t$ também remetem à ideia de riquezas e bens. O nome Otto proporciona um efeito paradoxal dentro da cenografia do conto, pois o protagonista não possui bens, nem a aura do nome que evidencia a origem nobre ou as qualidades boas e admiráveis de uma classe dominante. Otto não é lorde, nem padre, não tem sobrenome evidenciado na narrativa, tampouco pertence às esferas onde circulam os doutores, como é chamado pelo homem, "doutor Otto", num tom de deboche e escárnio. O título de doutor, dado às pessoas de posse, de bens e consequentemente de prestígio social, faz-nos remeter novamente ao conto O outro, de Rubem Fonseca.

A insônia que Otto sofre também faz dialogar com as narrativas já consagradas nacionalmente, como as de Graciliano Ramos, que tem o próprio conto intitulado Insônia, no qual o narrador-protagonista também é acometido pelas preocupaçóes da urbe moderna, e como Os ratos, de Dyonélio Machado, no qual os personagens sofrem com noites mal dormidas diante de preocupaçóes e de privaçóes, tanto da vida urbana, quanto do trabalho, que coincidem. Otto também é um pobre que tem o sono privado, e a pobreza que lhe cerca monta um cenário sufocante, fechado, dominado por outros homens, e assim também se percebe classes que dominam classes, vê-se a dominação, que, como aponta Michel Foucault (2007), não é mais uma relação, tampouco o lugar onde ela se exerce é um lugar. 
Insônia, de Roniwalter Jatobá, é uma narrativa breve que evidencia uma série de elementos da pobreza e do trabalho, a exemplo do pai de Otto, que é apenas mais um que morre na construção (retomando a canção de Chico Buarque). A pobreza mostrada no conto é um náo lugar, contando a pobreza das urbes brasileiras, a qual aparece em todos os lugares. No entanto, há uma força dominante que tenta deixá-la (e consegue) em lugar periférico, mas essa pobreza nas periferias já não cabe e não se contém. $\mathrm{O}$ pobre/o trabalhador se desloca de um lugar ao outro: é centro-periférico na atividade laboral, é periférico-central no descanso. Mas que descanso, uma vez que nos deslocamentos o trabalhador e pobre deve estar atento, para não ser surpreendido como Otto no meio de uma noite de insônia. Em uma caminhada na qual deveria aparecer o sono, surge a violência, declarando que Otto pode ser exaurido, não somente pelas condiçóes miseráveis em que vive, como também pelo trabalho, que não lhe traz dignidade, e por homens armados que determinam até onde pode ir e em que momento pode circular.

A narrativa também deixa notório o não tempo da pobreza nas urbes brasileiras, pois não apresenta um índice de tempo. De forma similar, a pobreza no Brasil é uma continuidade, desde a época colonial, que deixa uma herança, a qual condiciona cor e classe, mas que também se estende ao período da industrializaçáo, da ditadura, da retomada da democracia até a contemporaneidade. $\mathrm{O}$ conto não revela a cor dos personagens, há uma não cor, embora a classe social e a cor estejam relacionadas no Brasil, pois atinge de modo impactante a população negra. Todavia, no conto, faz-se notar que a periferia é ou pode ser habitada por todas as etnias.

Otto é um ser humano exaurido, acometido por uma série de violências, pela exclusão, pela desaprovação e pela condenação. Não sabe o motivo das agressōes, nem quem as comete. No conto, é dúbia a profissão dos agressores, mas não sua função: delimitam o espaço, vigiam e punem. A pobreza e seus opressores vivem uma guerra de baixa intensidade, uma guerra vergonhosa $\mathrm{e}$ declarada contra a pobreza e o pobre, o qual é a vítima sacrificial predestinada. Na modernidade, a pobreza é, assim, combatida pelo capitalismo, porque é um espelho no qual ninguém deseja se ver. A pobreza, a miséria e o trabalhador são vistos como imagens medonhas, as quais todos devem evitar e, se possível, executar ou exaurir sem culpa.

\section{Considerações finais}

Percebe-se a pobreza, o pobre, o trabalho, o trabalhador, o homo sacer, o excluído, o exaurido, em diversos momentos de crise no Brasil. Todavia, há uma visibilidade ainda maior na atualidade, quando se depara com enunciados de autoridades, num tom regulador, afirmando que a universidade não é 
para todos ${ }^{20}$, ou pelo desmonte, em 2017, das bases da Consolidaçáo das Leis Trabalhistas, que, por sua vez, instituíram e organizaram os contratos de trabalho desde a década de 1940, por exemplo. Isso quer dizer que estamos a caminho de uma regularização. Todas essas açôes ficam ainda mais em realce quando se fala que o Brasil entrou novamente no quadro da pobreza extrema e da fome. Cabe refletir que o slogan do Governo Federal durante o mandato da presidenta Dilma Rousseff, Um país rico é um país sem pobreza, não era uma frase óbvia e tomava um sentido necessário diante das desigualdades da sociedade, que continuam a vitimizar pobres e trabalhadores, privando-os de um mínimo bem-estar. Óbvio, ainda é a situação de pobreza, miséria e fome que muitos cidadáos, de certa forma invisíveis, continuam passando.

Todo o silêncio e a desfaçatez de classe podem ser quebrados pela literatura, a qual, por meio da representação, pode fazer emergir aquilo que tanto se quer recalcar, esconder e condenar, isto é, a pobreza e com ela os pobres, o trabalho e com ele os direitos dos trabalhadores.

Faz-se significativo retomar dois pontos. O primeiro é a própria etimologia da palavra miséria e sua raiz "moral", que já é habitada pela rejeiçáo, desaprovação, exclusão e condenação. O segundo é a questão da metáfora do naufrágio, pois o gozo que o espectador tem, em função da distância que lhe separa das vítimas, é algo ultrapassado, uma vez que Blumenberg usa a subversão dessa metáfora para dizer que na modernidade o espectador está embarcado, isto é, o espectador também é o náufrago. Portanto, o prazer, o gozo que se sente pelo distanciamento da pobreza e do trabalho é algo prémoderno, arcaico, contudo caracteriza a cultura brasileira ao longo do tempo.

20 O ex-ministro da educação, Rodrigo Vélez, no dia 28 de janeiro de 2019, declarou que "a universidade não é para todos", a qual teve uma repercussão negativa. Apesar do impacto negativo, o ministro ratificou a mesma afirmação em discursos posteriores. 
Referências

AGAMBEN, Giorgio. Homo sacer: o poder soberano e a vida nua. Belo Horizonte: Editora UFMG, 2007.

BLUMENBERG, Hans. Naufragio con spettatore: paradigma di una metafora dell'esistenza. Bologna: Il Mulino, 1985.

CASTIGLIONI, Luigi; MARIOTTI, Scevola. Dizionario della lingua latina. Torino: Loescher, 1990.

CORTELAZZO, Manlio; ZOLLI, Paolo. Il nuovo etimologico. Bologna: Zanichelli, 1999.

FONSECA, Rubem. Feliz Ano Novo. São Paulo: Companhia das Letras, 1989.

FOUCAULT, Michel. Vigiar e punir: nascimento da prisão. Petrópolis: Editora Vozes, 2009.

. Microfísica do poder. Rio de Janeiro: Graal, 2007.

JATOBÁ, Roniwalter. Contos antológicos de Roniwalter Jatobá. Organização e seleção de texto de Luiz Ruffato. São Paulo: Nova Alexandria, 2009.

HAN, Byung-Chul. Sociedade do cansaço. Rio de Janeiro: Editora Vozes, 2018.

LACAN, Jacques. O seminário (livro 5): as formaçôes do inconsciente. Rio de Janeiro: Zahar, 1999.

PRATOLINI, Vasco. Metello. Milano: Mondadori, 1969[1955].

REA, Ermanno. La dismissione. Roma: Nuova iniziativa editoriale, 2005[2002].

REIS, Zenir Campos. O mundo do trabalho e seus avessos: a questão literária. In: BOSI, Alfredo. Cultura brasileira: temas e situaçôes. 4a. ed. São Paulo: Ática, 2003.

SANTOS, Marcio Renato dos. A mais perfeita tradução. Rascunho, n. 115, jan. 2012. Disponível em: <http://rascunho.com.br/a-mais-perfeita-traducao/>. Acesso em: 29 abr. 2019.

SCHWARZ, Roberto. Os pobres na literatura brasileira. Sáo Paulo, SP: Brasiliense, 1983.

SPIVAK, Gayatri C. Pode o subalterno falar? Belo Horizonte: Editora UFMG, 2010. . Critica della ragione postcoloniale. Roma: Meltemi, 2004. . A Critique of Post-Colonial Reason. Cambridge: Harvard University Press, 1999. 
VECCHI, Roberto. Memorials of words: the victim in brazilian literature. In: CARVALHO, Vinicius M.; GAVIOLI, Nicola. Literature and Ethics in Contemporary Brazil, New York, Routledge, 2017.

. Literatura e trabalho: Brasília como obra. In: RESENDE, Beatriz; FINAZZI-AGRÓ, Ettore. Possibilidadesda nova escrita literária no Brasil. Rio de Janeiro: Revan, 2014.

Roberto Vecchi é professor de Literatura Portuguesa e Brasileira no Dipartimento di Lingue, Letterature e Culture Moderne da Universidade de Bolonha, coordenador da Cátedra Eduardo Lourenço (Camóes-Unibo), investigador associado no Centro de Estudos Sociais da Universidade de Coimbra e no Laboratório de Estudos Literários Avançados da Universidade Nova de Lisboa, pesquisador do CNPq, professor honorário de Estudos Lusófonos na School of Cultures, Languages and Area Studies na Universidade de Nottingham e presidente da Associação Internacional de Lusitanistas. E-mail: roberto.vecchi@unibo.it

Éderson de Oliveira Cabral é doutorando no Programa de Pós-graduação em Processos e Manifestaçóes Culturais na Universidade Feevale, com período sanduíche na Universidade de Bolonha, mestre em Linguística Aplicada e licenciado em LetrasPortuguês/Espanhol pela Universidade do Vale do Rio dos Sinos e especialista em Língua Espanhola pela Pontifícia Universidade Católica do Rio Grande do Sul.

Email: edercabral@feevale.br 